\title{
Endothelin-1 Expression in Prostate Needle Biopsy Specimens Correlated With Aggressiveness of Prostatic Cancer
}

\author{
Mojgan Asgari*1, Elham Eftekhar ${ }^{2}$, Maryam Abolhasani' ${ }^{1}$, Hossein Shahrokh ${ }^{3}$ \\ 1. Oncopathology Research Center, Iran University of Medical Science (IUMS), Tehran, Iran \\ 2. Sherkat Naft Hospital, Tehran, Iran
}

3. Uro Oncology Department, Hasheminejad Kidney Center, Iran University of Medical Sciences (IUMS), Tehran, Iran

\section{KEYWORDS}

Endothelin-1

Prostatic cancer

Prognosis

Needle biopsy

Article Info

Received 04 Apr 2017;

Accepted 04 Apr 2017;

Published Online 2017;

\section{ABSTRACT}

Background \& Objective: As the prostate adenocarcinoma is one of the most common malignant tumors in males, looking for a marker to effectively predict aggressiveness and metastatic potential in an apparently localized cancer in initial needle biopsy specimens can help the clinicians to make more appropriate decision for treatment, planning, and choosing appropriate targeted therapy. The present study assessed the value of Endothelin-1 expression to predict prognosis of prostatic cancer

Methods: In a cross sectional study, 83 patients who underwent radical prostatectomy in Hasheminejad Kidney Center in 2008 through 2012 were assigned to two groups including 43 with and 40 without extra-prostatic extension (EPE). Endothelin-1 staining was performed on Paraffin Embedded blocks of preoperative needle biopsies.

Results: The expression of Endothelin-1 increased in $72 \%$ of patients in the group with EPE $(\mathrm{P}<0.001)$. The group with Endothelin-1 positivity showed higher serum level of prostate specific antigen (PSA) $(p=0.039)$. Endothelin-1 expression was positive in $67 \%$ of patients with perineurial invasion $(\mathrm{P}<0.001)$. Adjusting the baseline variables of PSA and PN in a multivariable logistic regression model, the Endothelin-1 positivity could effectively predict EPE in patients with prostatic cancer (OR: 5.46, $\mathrm{p}=0.010)$.

Conclusion: Correlation of Endothelin-1 expression in needle biopsy specimens in expected with extra-prostatic extension of tumor in radical prostatectomy specimens, perineurial invasion and serum PSA level at the time of diagnosis.

Corresponding Information: Dr. Mojgan Asgari; Oncopathology Research Center, Iran University of Medical Science (IUMS), Tehran, Iran Tel: + 982181161 Email: mojgan_asgari@yahoo.com

Copyright (c) 2017, IRANIAN JOURNAL OF PATHOLOGY. This is an open-access article distributed under the terms of the Creative Commons Attributionnoncommercial 4.0 International License which permits copy and redistribute the material just in noncommercial usages, provided the original work is properly cited.

\section{Introduction}

According to annually published National Cancer Registration Report 2008-2009 of Iran, prostate cancer is the fourth most frequent cancer among male adults with an annual cause of death in 4.5 per 100,000 men in $\operatorname{Iran}(1,2,3)$. As there are no integrated national programs for screening and recording of prostate cancer, the incidence rate of this cancer might be more than these registered data (2). Despite the relatively high prevalence of this cancer in our region, most patients remained asymptomatic except in advanced stages of cancer that manifested by weight loss, urinary tract obstruction and skeletal bone pains. To screen and early detect, serum level of prostate specific antigen (PSA) in combination with digital rectal exam are used for suspected patients who referred for Ultrasound-Guided Transrectal Needle Biopsy (4). Preoperative PSA level, TNM staging, Gleason grade and surgical margins are now considered as major prognostic factors for prostate carcinoma. The second line factors include tumor volume, histologic type and DNA ploidy analysis and some biologic markers including ki67, p53, and p21 (5). One of the interesting and challenging biomarkers is Endothelin-1 (ET-1). Endothelin-1 is produced by many different cell types (6), including prostatic 
epithelium (7) and is known as one of the most potent endogenous vasoconstrictors with prolonged effects $(8,9)$. Elevated plasma level of this marker has been shown in patients with metastatic prostate cancer comparing the patients who are involved by organ-confined cancer as well as healthy people (10). Two receptor subtypes of endothelin-1 are Endothelin receptor $\mathrm{A}\left(\mathrm{ET}_{\mathrm{A}}\right)$ and Endothelin receptor $\mathrm{B}\left(\mathrm{ET}_{\mathrm{B}}\right)$. It has been demonstrated that the binding of Endothelin-1 to $\mathrm{ET}_{\mathrm{A}}$ can induce survival pathway, as well as induce cell proliferation by activating kinases such as epidermal growth factor, and inhibits apoptosis (10-11), while the activation of the $\mathrm{ET}_{\mathrm{B}}$ can result in clearance of circulating Endothelin-1 as well as stimulation of apoptosis. Endothelin-1 regulates neovascularization by controlling endothelial cell migration, proliferation, and invasion as well as induction of micro-vessel density and production of vascular endothelial growth factor in tumor cells $(12,13)$. On the other hand, Endothelin-1 inhibits apoptosis by modulation of cell survival pathways, such as PI3K-dependent AKT activation (15). In addition, endothelin-1 is a mitogenic factor for osteoblasts whereas results in reduced osteoclastic bone resorption, osteoclast motility and therefore plays an enhancing role in osteoblastic metastases $(14,15)$. In the few last decades, preliminary data from clinical trials on endothelin receptor antagonists such as Atrasentan in patients with prostate cancer have been encouraging; however they have not reached to a definite result as a consensus yet (17). In the present study, we aimed to investigate the association of Endothelin-1 expression by immunohistochemistry (IHC) on needle biopsies with different prognostic factors of prostatic cancer including extra-prostatic extension in radical prostatectomy specimens, serum level of PSA, and Gleason's score of the tumor.

\section{Material and Methods}

All radical prostatectomy specimens prepared in Hasheminejad Kidney Center in Tehran from 2008 to 2012 were retrospectively reviewed and 83 specimens selected were assigned in two groups including 40 patients with extra-prostatic extension and 43 patients without EPE. The preoperative $H \& E$ slides of the patients' needle biopsies were extracted and reviewed; in the present study, the paraffin blocks of needle biopsy cores which showed most involvement by tumor with highest Gleason's score were selected. Other study parameters which assessed were patients' age, initial serum level of PSA, Gleason's score, perineurial invasion and adjacent organs involvement (table 1). The exclusion criteria included small amount of tissue in paraffin blocks and crushed specimens, and unavailable data on preoperative biopsy specimen or serum PSA level. Immunohistochemistry was performed using the envision method (Abcam company, USA) on formalin fixed tissue sections and pretreated with heat-induced epitope retrieval for Endothelin-1 using Anti-Endothelin- 1 antibody (TR.ET.48.5) (ab2786). Normal colonic mucosa was used as positive control and slides with omitted primary antibody as negative control.

IHC stained sections were classified in four groups in a semi-quantitative scoring system based on intensity of cytoplasmic staining in tumor cells: 0 as negative; 1 as weak cytoplasmic staining in more than half of the tumoral cells; 2 as moderate staining in more than half of tumor cells; and 3 as strong staining in more than half of tumor cells. Scores 0 and 1 were considered as low Endothelin-1 expression or negative and scores 2 and 3 as high Endothelin-1 expression or positive $(15,16)$.

Results were presented as mean \pm standard deviation (SD) for quantitative variables and were summarized by absolute frequencies and percentages for categorical variables. Categorical variables were compared using chi-square test or Fisher's exact test when more than $20 \%$ of cells with expected count of less than 5 were observed. Quantitative variables were also compared with Mann- Whitney U test. Multivariable logistic regression analysis was used to assess the value of Endothelin-1 to predict tumor-related outcome. Statistical significance was determined as a $p$ value of $\leq 0.05$. All statistical analysis was performed using SPSS software (version 16.0, SPSS Inc., Chicago, Illinois). 
Table 1. Frequency and Percentage of Pathology Findings and the Result of staining

\begin{tabular}{lcc}
\hline Variable & & Frequency (\%) \\
\hline \multirow{3}{*}{ Gleason's score } & 6 & $28(33.7 \%)$ \\
\cline { 2 - 3 } & 7 & $33(39.8 \%)$ \\
\cline { 2 - 3 } Extraprostatic Extension & 8 & $17(20.5 \%)$ \\
\cline { 2 - 3 } Perineurial invasion & 9 & $4(4.8 \%)$ \\
\cline { 2 - 3 } & 10 & $1(1.2 \%)$ \\
\hline \multirow{2}{*}{ IHC Score for ET-1 } & Positive & $43(51.8 \%)$ \\
\cline { 2 - 3 } & Negative & $40(48.2 \%)$ \\
\cline { 2 - 3 } & Positive & $43(51.8 \%)$ \\
\cline { 2 - 3 } & Negative & $40(48.2 \%)$ \\
\hline
\end{tabular}

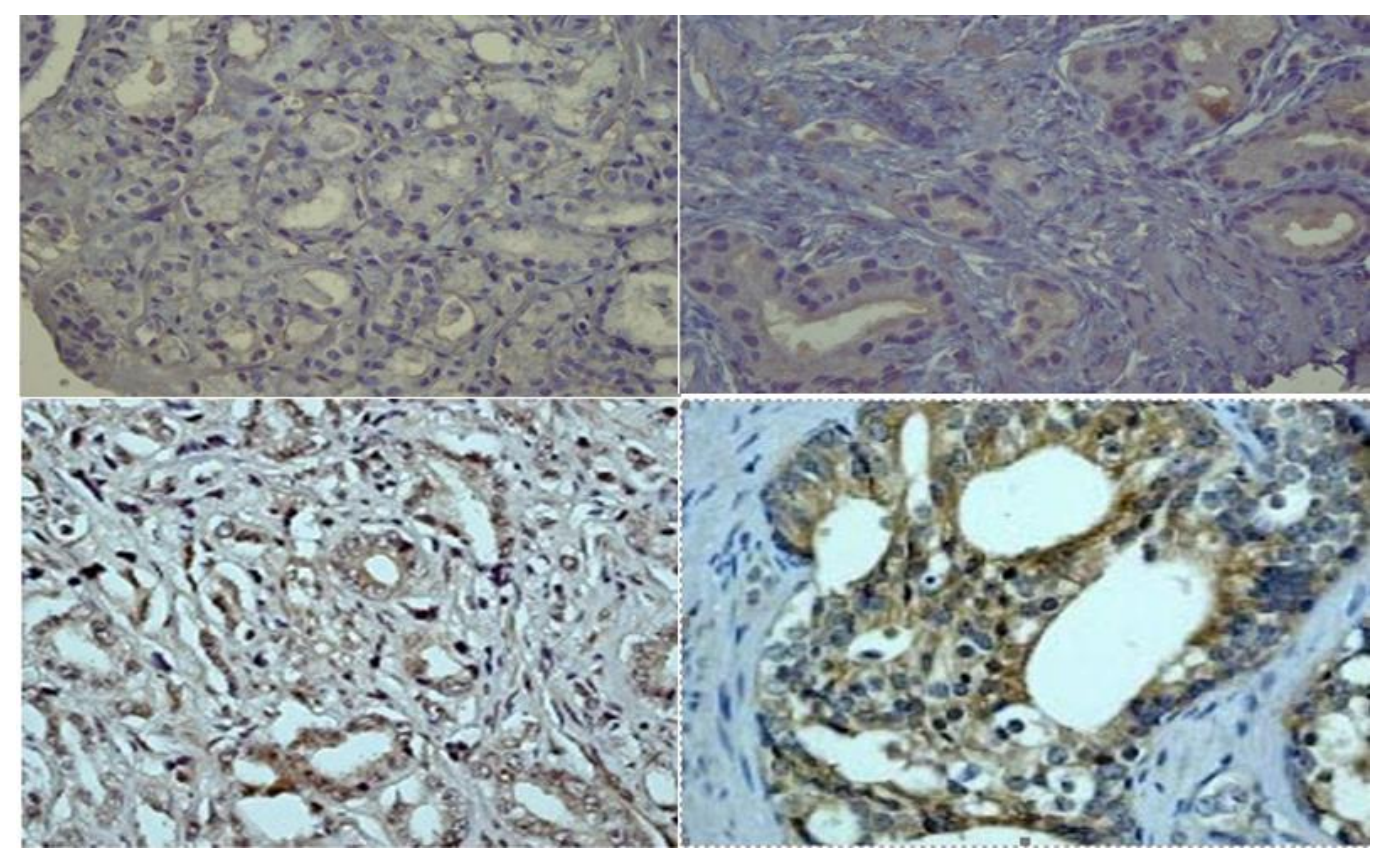

Fig 1. a) Score 0; no immunoreactivity in tumor cells b) Score 1; weak cytopasmic staining in more than half of tumor cells. c) Score 2; moderate cytopasmic staining in more than half of tumor cells. d) Score 3; severe cytopasmic staining in more than half of tumor cells.

\section{Results}

Pathologic findings and the result of staining are summarized in Table 1. There was no difference in mean age of patients in the groups with and without positive Endothelin-1 (65.6 \pm 7.4 years versus 64.5 \pm 8.3 years, $p=0.533$ ). Of 43 patients without EPE, 26.0\% had positive Endothelin-1 expression, while $72.0 \%$ of those with EPE have shown to be Endothelin-1 positive with a significant difference $(P<0.001)$. Forty three cases had perineurial invasion including $33.0 \%$ in the group with

negative Endothelin-1 expression and 67\% in those with positive Endothelin-1 expression. In this regard, $73 \%$ of patients without perineurial invasion were negative for Endothelin-1. The patients group with positive Endothelin-1 expression had a mean serum PSA level of $44.6 \pm$ $10.2 \mathrm{ng} / \mathrm{ml}$ while, the mean serum level of this marker in the group with negative Endothelin-1 expression was $18.6 \pm 6.7 \mathrm{ng} / \mathrm{ml}$ with a significant difference $(\mathrm{P}=0.039)$. In total, 28 patients showed Gleason's score 6 that of them, 32.1\% were 
positive for Endothelin-1. Overall, Endothelin-1 positivity was shown in $54.5 \%$ of patients with Gleason score 7, in $58.8 \%$ of patients with Gleason score 8 , in $50.0 \%$ of patients with Gleason score 9, and also in $100 \%$ of those with Gleason score 10 with no inter-group difference $(p=0.327)$. Multivariate logistic regression analysis was performed to assess the role of positive Endothelin1 to predict EPE. Adjusting the baseline variables of PSA and PN, the Endothelin-1 positivity could effectively predict EPE in patients with prostatic cancer (OR: 6.04, $p=0.010$ ). The result of were summarized in table 2 .

Table 2. ET-1 Expression Regarding Patient's Age, Serum PSA and Pathologic Findings.

\begin{tabular}{|c|c|c|c|c|c|}
\hline Variable & Group & ET-1 positive & ET-1 negative & P value & OR $(95 \% \mathrm{CI})$ \\
\hline Age & - & $64.5 \pm 8.3$ & $65.6 \pm 7.4$ & 0.533 & - \\
\hline PSA, ng/ml & - & $18.6 \pm 6.7$ & $44.6 \pm 10.2$ & $<0.001$ & - \\
\hline \multirow{2}{*}{ Perineurial Invasion } & negative & $11(27.5 \%)$ & $29(72.5 \%)$ & \multirow{2}{*}{$<0.001$} & \multirow{2}{*}{$5.46(1.41-14.10)$} \\
\hline & positive & $29(67.4 \%)$ & $14(32.6 \%)$ & & \\
\hline \multirow{5}{*}{ Gleason Score } & 6 & $9(32.1 \%)$ & $19(67.6 \%)$ & \multirow{5}{*}{0.261} & \\
\hline & 7 & $18(54.5 \%)$ & $15(45.5 \%)$ & & \\
\hline & 8 & $10(58.8 \%)$ & $7(41.2 \%)$ & & \\
\hline & 9 & $2(50 \%)$ & $2(50 \%)$ & & \\
\hline & 10 & $1(100 \%)$ & 0 & & \\
\hline \multirow{2}{*}{$\begin{array}{c}\text { Extraprostatic } \\
\text { Extension }\end{array}$} & negative & $11(25.6 \%)$ & $32(74.4 \%)$ & \multirow{2}{*}{$<0.001$} & \multirow{2}{*}{$7.67(1.58-20.30)$} \\
\hline & positive & $29(72.5 \%)$ & $11(27.5 \%)$ & & \\
\hline
\end{tabular}

\section{Discussion}

As the first available specimen of prostate cancers are needle biopsy specimens, choosing the appropriate therapeutic plan is mainly based on pathologic findings in small representatives of prostate cancer. So it is important to use all informative markers in pathology specimens to predict tumor behavior even when the examined tissue specimen is too small. A complete pathology report considering all prognostic markers would result in better handling of cancer; and using different alternatives for radical prostatectomy including radiotherapy or targeted therapy with less morbidity risk especially in patients with metastatic cancer. In recent years, several biomarkers associated with prostate cancer were examined such as endothelin-1. This marker has been identified as a promoter of tumor angiogenesis and cell proliferation and is a challenging in recent advances of targeted therapy for several human malignancies including malignant melanoma, breast and cervical carcinoma (17). It was firstly isolated and characterized as a new peptide produced by porcine aortic endothelial cells by a graduate student named Masashi Yanagisawa (8). In 1995, Nelson and his colleagues showed significant elevation of immunoreactive endothelin- 1 concentration in men with metastatic prostate cancer. They showed that human prostate cancer cell line produces endothelin1 messenger RNA and secretes immunoreactive endothelin-1. They selected 14 patients with confined prostate cancers and 16 patients with metastatic cancer and found endothelin-1 positivity in $87 \%$ of patients (10). Functions of endithelins and their receptors referred as endothelin axis in the growth and progression of various tumors trigger the clinical trials of endothelin receptor antagonists such an atrasentan in prostate cancer and the results was encouraging (20).

In our study, we attempted to find a diagnostic tool to identify apparently localized aggressive prostate cancers in needle biopsy specimens. Our findings showed that endothelin-1was more expressed in tumoral cells of prostate cancer with EPE (72\%) compared to the cancer specimens without EPE (26\%). There was also a correlation between serum PSA levels and expression of ET-1 in tumor cells. Endothelin-1 was also more positive in the presence of perineurial invasion comparing the specimens without it (67\% versus $27 \%$ respectively), but logistic regression analysis showed that the correlation of PSA level and perineurial invasion 
was dependent to the presence of EPE. We found no association between Endothelin-1 expression and patients' age or tumor Gleason score. In 2007, Gorada et al assessed 120 cases of prostate cancer and found immunoreactivity to endothelin-1 in $72 \%$ of patients as well as a positive relationship between endothelin-1 expression and PSA levels but not with tumor Gleason score. They also concluded that high endothelin-1 expression was correlated with increased pathologic stage and tumor recurrence (16). In 2010, Menard et al selected 94 patients with prostate adenocarcinoma and reported endothelin-1 positivity in $50 \%$ of them. They found a correlation between endothelin-1 expression, PSA higher than $10 \mathrm{ng} / \mathrm{ml}$ and Gleason score higher than 7 with EPE (15). Our results were supportive of Menard \& Gorada study about presence of correlation between endothelin-1 expression and PSA levels and EPE. With regard to Gleason score, our results were similar to the report by Gorada, but in contrary to the results pointed by Menard. Correlation between endothelin-1 expression and perineurial invasion was not assessed by them. The study by Prez et al in 2010 performed on 68 radical prostatectomy specimens that showed higher intensity of endothelin-1 expression in specimens with positive EPE. They concluded that prostate cancer biopsy expression was an independent prognostic factor of high extracapsular stage (21). Another study by Montironi et al in 2007 showed that endothelin-1 expression was not limited to the late prostate cancer phases and was also seen in HGPIN found in radical prostatecromy and also clinically insignificant prostate cancers in cystoprostatectomy specimen; however the number of their cases was limited in each groups (22). In total, it seems that the contradictory results in the studies may be due to the difference in staining or heterogeneous nature of the tumor and the return of racial differences that should be more investigated.

\section{Conclusion}

Considering these results, we suggest using endothelin-1 expression as a complementary option in assessment and report of prostate needle biopsies in prostate adenocarcinoma to help the physician to make the best decision for affected patients, decrease mortality and morbidity by preventing less appropriate radical prostatectomy in aggressive tumors and also selecting patients for endothelin-1 blockade therapy.

\section{Acknowledgment}

Technical part of this work was performed in pathology laboratory of Firoozgar hospital and Shahid Hsheminejad Kidney Center.

\section{Conflict of Interest}

The authors declare that there was no conflict of interest.

\section{References}

1. Iranian Annual of National Cancer Registration Report 2008-2009:120-121.

2. Mousavi SM, Gouya MM, Ramazani R, Davanlou M, Hajsadeghi N, Seddighi Z. Cancer incidence and mortality in Iran. Ann Oncol. 2009; 20(3):556-63.

3. Kolahdoozan S, Sadjadi A, Radmard AR, Khademi H. Five Common Cancers in Iran. Arch Iran Med. 2010;13(2):143-6.

4. Benson MC, Whang IS, Olsson CA, et al. The use of prostate specific antigen density to enhance the predictive value of intermediate levels of serum prostate specific antigen. J Urol 1992;147(3 Pt 2):817-21

5. College of American Pathologists. Protocol for the Examination of Specimens from Patients with Carcinoma of the Prostate Gland 2009 ;October

6. Rubanyi GM, Polokoff MA. Endothelins:molecular biology, biochemistry, pharmacology, physiology, and pathophysiology. Pharmacol Rev 1994;46(3):325-415.

7. Langenstroer $\mathrm{P}$, Tang R, Shapiro E et al. Endothelin-1 in the human prostate: tissue levels, source of production and isometric tension studies. J Urol 1993; 149: 495-9

8. Yanagisawa M, Kurihara H, Kimura S et al. A novel potent vasoconstrictor peptide produced by vascular endothelial cells. Nature. 1988 31;332(6163):411-5.

9. Nelson JB, Carducci MA. The role of endothelin-1 and endothelin receptor antagonists in prostate cancer. BJU Int. 2000;85 Suppl 2:45-8. 
10. Nelson JB, Hedican S, George D, Reddi A, Piantadosi A, Eisenberger M, et al. Identification of endothelin-1 in the pathophysiology of metastatic adenocarcinoma of the prostate. Nat Med. 1995;1(9):944-9.

11. Joel B Nelson, Michael S Udan,Georgi Guluri ,Beth R Pflug. Endothelin-1 Inhibits Apoptosis in Prostate Cancer Neoplasia 2005; 7(7): 631-7.

12. Bagnato A, Rosano L. The endothelinaxis in cancer. Int J Biochem Cell Biol. 2008;40(8):144351.

13. Bagnato A, Spinella F, Rosano L. Emerging role of the endothelin axis in ovarian tumor progression. Endocr Relat Cancer 2005;12(4):76172.

14. Guise TA, Mohammad KS, Clines G et al. Basic mechanisms responsible for osteolytic and osteoblastic bone metastases. Clin Cancer Res. 2006 Oct 15;12(20 Pt 2):6213s-6216s.

15. Menard J, Durlach A, Barbe C, Joseph K, Lorenzato M, Azemar MD, Perez T, Birembault P, Staerman F. Endothelin-1: a predictor of extracapsular extension in clinically localized prostate cancer? BJU Int. 2011;108(2 Pt 2):E104-9. Epub 2010 Nov 23.

16. Godara G, Pecher S, Jukic Dm, D'Antonio JM, et al. Distinct Patterns of Endothelin Axis Expression in Primary Prostate Cancer. Urology. 2007;70(1):209-15.
17. Bagnato A, Natali PG. Endothelin receptors as novel targets in tumor therapy. J Transl Med. 2004 27;2(1):16.

18. Nelson JB, Love W, Chin JL, Saad F, Schulman CC, Sleep DJ, et al. Phase 3, randomized, controlled trial of atrasentan in patients with nonmetastatic, hormone-refractory prostate cancer. Cancer. 2008 1;113(9):2478-87.

19. S. Yount, D. Cella, P. Mulani, D. Sleep, A. Allen, J. Isaacson, S. et al. Impact of atrasentan on prostate-specific outcomes with hormone refractory prostate cancer patients; Journal of Clinical Oncology 2004 ASCO Annual Meeting Proceedings. Vol 22, No 14S (July 15 Supplement), 2004: 4582

20. Nelson J, Bagnato A, Battistini B, Nisen P The endothelin axis: emerging role in cancer. Nat Rev Cancer. 2003;3(2):110-6.

21. Perez T, Menard J, Joseph K, Birembaut P, Staerman F. Prostate biopsies endothelin-1 expression: pt3a stage prognostic factor? Prog Urol. 2010;20(5):364-8.

22. Montironi R, Mazzucchelli R, Barbisan F, Stramazzotti D, Santinelli A, Lòpez Beltran A. et al. Immunohistochemical expression of endothelin1 and endothelin-A and endothelin-B receptors in high-grade prostatic intraepithelial neoplasia and prostate cancer." Eur Urol. 2007 ;52(6):1682-9. Epub 2007 Mar 12.

\section{How to Cite This Article:}

Asgari M, Eftekhar E, Abolhasani M, Shahrokh H. Endothelin-1 Expression in Prostate Needle Biopsy Specimens Correlated With Aggressiveness of Prostatic Cancer. Iran J Pathol. 2017; 12(2): 171-176. 